\title{
Editorial on Special Issue Electrolysis Processes
}

\author{
Tanja Vidaković-Koch $(\mathbb{1}$ \\ Electrochemical Energy Conversion, Max Planck Institute for Dynamics of Complex Technical Systems, \\ D-39106 Magdeburg, Germany; vidakovic@mpi-magdeburg.mpg.de
}

Received: 7 May 2020; Accepted: 7 May 2020; Published: 14 May 2020

Renewable energies such as solar, hydro or wind power are in principal abundant but subjected to strong fluctuations. Therefore, development of new technologies for storage of these renewable energies is of special interest. Electrochemical technologies are ideal candidates for the use of excess current, and consequently an increased electrification of chemical processes is expected. In this respect, there are different pathways to utilize excess current electrochemically. Intermediate energy storages in (a) chemical energy carriers like hydrogen via water electrolysis or (b) electrochemical energy storage devices like batteries are perhaps most accepted and discussed solutions. Additionally, excess current can be used with the main goal not to be stored for later use, but to solve some environmental issue or for construction purposes. Possible applications are waste water treatment and electromachining. The article collection in this special issue consists of one review paper and nine original research papers and discusses these topics in more detail. As a Guest Editor of this special issue, I thank all authors for their contributions and wish all readers interesting insights and new inspirations for their works.

\section{Electrolysis Processes for Intermediate Energy Storage in Chemical Energy Carriers Like Hydrogen-Water Electrolysis}

There are three main technologies for water electrolysis: alkaline water electrolysis (AEL), proton exchange membrane (or polymer electrolyte membrane) electrolysis (PEMEL), and solid oxide electrolysis (SOEL), with two of them (AEL and PEMEL) at high technical readiness level. Despite these facts and intensive discussions on water electrolysis as a key technology for generation of pure hydrogen using renewable electricity, currently less than $4 \%$ of hydrogen originates from electrolysis, with the main part originating not from water but from from chlor-alkali electrolysis where hydrogen is a by-product of chlorine production [1]. Broad introduction of cost competitive and preferably zero carbon routes for hydrogen production is urgently required. In the review paper of Brauns and Turek [1], some of the main challenges hindering broader penetration of water electrolysis are discussed with a focus on AEL. As the authors write, AEL is a key technology for large-scale hydrogen production powered by renewable energy. However, conventional electrolyzers are designed for operation at fixed process conditions, therefore, the implementation of fluctuating and highly intermittent renewable energy is challenging. Their system analysis enabled important insights and a roadmap for more energy efficient systems. According to these authors, in order to be competitive with the conventional path based on fossil energy sources, each component of a hydrogen energy system needs to be optimized to increase the operation time and system efficiency. They stress that by combining AEL with hydrogen storage tanks and fuel cells, power grid stabilization can be achieved. As a consequence, the conventional spinning reserve can be reduced, which additionally lowers the carbon dioxide emissions.

Water electrolysis was also in the focus of Vorhauer et al. [2] and Altaf et al. [3]. One of the reasons for lowering energy efficiency of water electrolysis at high current densities is mass transport limitation in porous transport layers (PTL) of water electrolyzers. This issue is intrinsic for both low temperature water technologies (AEL and PEMEL) and is likely caused by the counter current transport of oxygen gas produced at the anode to the educt (water or $\mathrm{OH}$ - ions). In two publications by 
Vorhauer et al. [2] and Altaf et al. [3], this issue was studied with the help of porous network theory and with special emphasis on PEMEL. Pore network models (PNM) are powerful tools to simulate invasion and transport processes in different porous media with applications across different disciplines like geology, chemical engineering as well as electrochemical engineering (e.g., fuel cell applications). In their pioneering contribution, Vorhauer et al. [2] described a first application of a PNM of drainage for the prediction of the oxygen and water invasion process inside the anodic PTL at high current densities. According to the authors, in the simulation with narrow pore size distribution, the volumetric ratio of the liquid transporting clusters connected between the catalyst layer and the water supply channel is only around 3\% of the total liquid volume contained inside the pore network at the moment when the water supply route through the pore network is interrupted; whereas around $40 \%$ of the volume is occupied by the continuous gas phase. The majority of liquid clusters are disconnected from the water supply routes through the pore network if liquid films along the walls of the porous transport layer are disregarded. Moreover, these clusters hinder the countercurrent oxygen transport. They also based on these sketches a new route for the extraction of transport parameters from Monte Carlo simulations, incorporating pore scale flow computations and Darcy flow.

In the publication by Altaf et al. [3], results from Monte Carlo pore network simulations are shown and compared qualitatively to microfluidic experiments from literature. The literature-based experimental invasion patterns of different types of PTLs, such as felt, foam or sintered, have shown good agreement with pore network simulations. Additionally, the impact of pore size distribution on the phase patterns of oxygen and water inside the pore network was studied. These very promising results further supported pore network modeling as a valuable tool for gaining new insights in the transport processes in porous layers during water electrolysis.

Reliable models of gas-liquid equilibria in aqueous electrolytes are of significant importance for proper description of many electrochemical processes including gases as products or reactants (major examples are water, brine, $\mathrm{CO}_{2}$ electrolysis, but also reactions in polymer electrolyte fuel cells). Nabipour et al. [4] proposed a novel solubility estimation tool for gases in aqueous electrolyte solutions based on an extreme learning machine (ELM) algorithm. Although the presented study cases are not directly relevant for water electrolysis, the here developed novel methodology has a potential to be transferred to more relevant examples for electrochemical applications.

\section{Electrolysis Processes for Intermediate Energy Storage in Electrochemical Energy Storage Devices}

Different types of electrochemical energy storage devices are discussed in the framework of intermediate energy storage from renewables. Common examples are rechargeable batteries like Li-ion or redox flow batteries. In this special issue, two less discussed options are described, a so-called acid-base flow battery [5] and supercapacitors [6]. An acid-base flow battery is proposed by Xia et al. [5]. This very interesting solution is based on reverse electrodialalysis with bi-polar membranes. During charging, the system operates in electrolysis mode; hydrogen and oxygen evolution reactions take place at the cathode and anode, respectively; and acid and base solutions are regenerated in corresponding compartments. Alike normal water electrolysis, the two half-reactions take place at different $\mathrm{pH}$ values (acidic and alkaline conditions). During discharge, neutralization of acid and base produces electricity in the process of reverse electrodialysis with bipolar membranes in an apparently fairly overlooked flow battery concept. The authors demonstrated this concept with stack experiments, consisting of 5 to 20 repeating cell units at lab scale. The first results are very promising and the studied system shows already energy density in the similar range of redox flow batteries. The challenges and measures to further increase energy efficiency of this new type of acid-base flow battery are discussed.

Due to the high power fluctuations that are inherent to renewable energy sources, the dynamics of the storage media is of great importance when designing storage concepts for renewable energy. Electrochemical storage systems showing even better dynamics than batteries are so-called supercapacitors. These devices can be quickly charged and discharged, but have lower energy density 
than batteries. Still, due to their favorable dynamics, they can be a valuable addition to batteries in the framework of intermediate energy storage from renewables. The storage capacity of these devices depends largely on employed materials. In this special issue, development of novel electrode material for supercapacitor application based on pseudocapacitance is discussed. Guragain et al. [6] developed a large-surface-area $\mathrm{MCO}_{2} \mathrm{O}_{4}$ material in which a tubular microstructure leads to a noticeable pseudocapacitive property with the excellent specific capacitance value exceeding $407.2 \mathrm{~F} / \mathrm{g}$ at $2 \mathrm{mV} / \mathrm{s}$ scan rate. In addition, a Coulombic efficiency $100 \%$ and excellent cycling stability with $100 \%$ capacitance retention was noted even after 5000 cycles. These tubular $\mathrm{MCO}_{2} \mathrm{O}_{4}$ microstructures display peak power density exceeding $7000 \mathrm{~W} / \mathrm{kg}$. Based on these authors, the superior performance of the tubular $\mathrm{MCO}_{2} \mathrm{O}_{4}$ microstructure electrode is attributed to their high surface area, adequate pore volume distribution, and active carbon matrix, which allows effective redox reaction and diffusion of hydrated ions.

\section{Electrolysis Processes Aiming to Solve Environmental Issues or for Construction Purposes}

In addition to clean energy, the requirement of clean water is of the upmost importance for prosperity and healthiness of the world population. With respect to water, one issue is water scarcity, causing 1.2 billion people to suffer from a lack of water [7]. Another issue is industry or domestic-based water pollution [7-9]. Due to the widespread use of chlorinated compounds such as $\mathrm{HCl}, \mathrm{NaCl}$, and $\mathrm{MgCl}_{2}$ in the industry, the content of chloride ion in wastewater is increasing [8,9]. If it is discharged directly to the environment, diverse environmental issues will be created with consequences for water resources, soil and human health. At present the most widely used method for $\mathrm{Cl}^{-}$waste water treatment is chemical precipitation. Electrochemical oxidation processes have a high potential for efficient removal of even trace amounts of $\mathrm{Cl}^{-}$due to high degradation efficiency, no secondary pollution, modularity, flexibility, and use of renewable electricity, which can contribute to stabilization of the energy grid. The degradation efficiency and degradation products of the electrochemical oxidation process change with the anode material, therefore, two articles by $\mathrm{Xu}$ et al. [8] and Liu et al. [9] discuss the development of new anode materials for electrochemical $\mathrm{Cl}^{-}$removal. $\mathrm{Xu}$ et al. [8] studied porous $\mathrm{Ti} / \mathrm{SnO}_{2}-\mathrm{Sb}_{2} \mathrm{O}_{3} / \mathrm{PbO}_{2}$ electrodes for electrocatalytic oxidation of chloride ions by varying different parameters. The results have shown that $\mathrm{Ti} / \mathrm{SnO}_{2}-\mathrm{Sb}_{2} \mathrm{O}_{3} / \mathrm{PbO}_{2}$ electrodes with $150 \mu \mathrm{m}$ pore size had the best removal effect on chloride ions with removal ratios amounting up to $98.5 \%$ when the initial concentration of chloride ion was $10 \mathrm{~g} \mathrm{~L}^{-1}$. The advanced electrode structure minimized oxygen evolution as a side reaction, which further increased the removal effect of chloride ions. In the further publication, Liu et al. [9] studied different material combinations. The porous Ti/Sb-SnO $/ 2 / \mathrm{Ni}-\mathrm{Ce}-\mathrm{PbO}_{2}$ electrode was prepared by using a porous Ti plate as a substrate, an $\mathrm{Sb}$-doped $\mathrm{SnO}_{2}$ as an intermediate, and $\mathrm{a} \mathrm{PbO}_{2}$ doped with $\mathrm{Ni}$ and $\mathrm{Ce}$ as an active layer. The authors studied also the mechanism of electrochemical dechlorinating. They found out that the increase of $\mathrm{OH}^{-}$inhibits the degradation of $\mathrm{Cl}^{-}$.

In addition to inorganic catalysts, oxidation of mainly organic pollutants in the waste water treatment can be performed with the help of biological catalysts, for example microorganisms. These systems can operate either as microbial fuel cells (MFC) or in electrolysis mode. A contribution by Muddemann et al. [7] discuss current challenges in the scale up of these systems, with special emphasis on oxygen reducing cathode. The authors demonstrated a strong increase in the MFC performance and long term stability upon improving catalyst coating quality.

Finally Liu et al. [10] describe electrochemical discharge machining (ECDM) as an effective way to fabricate micro structures in non-conductive materials, such as quartz glass and ceramics. This has significant importance for the development of micro electromechanical systems (MEMS), such as micro reactors and micro medical devices, which often consist of the micro structures of nonconductive materials, such as glass, ceramics and silicon nitride and which are difficult to fabricate using the traditional machining methods. 
Funding: This research received no external funding.

Conflicts of Interest: The author declares no conflict of interest.

\section{References}

1. Brauns, J.; Turek, T. Alkaline water electrolysis powered by renewable energy: A review. Processes 2020, 8, 248. [CrossRef]

2. Vorhauer, N.; Altaf, H.; Tsotsas, E.; Vidakovic-Koch, T. Pore network simulation of gas-liquid distribution in porous transport layers. Processes 2019, 7, 558. [CrossRef]

3. Altaf, H.; Vorhauer, N.; Tsotsas, E.; Vidaković-Koch, T. Steady-state water drainage by oxygen in anodic porous transport layer of electrolyzers: A 2D pore network study. Processes 2020, 8, 362. [CrossRef]

4. Nabipour, N.; Mosavi, A.; Baghban, A.; Shamshirband, S.; Felde, I. Extreme learning machine-based model for solubility estimation of hydrocarbon gases in electrolyte solutions. Processes 2020, 8, 92. [CrossRef]

5. Xia, J.; Eigenberger, G.; Strathmann, H.; Nieken, U. Acid-base flow battery, based on reverse electrodialysis with Bi-polar membranes: Stack experiments. Processes 2020, 8, 99. [CrossRef]

6. Guragain, D.; Zequine, C.; Gupta, R.; Mishra, S. Facile synthesis of bio-template tubular $\mathrm{MCo}_{2} \mathrm{O}_{4}(\mathrm{M}=\mathrm{Cr}$, $\mathrm{Mn}, \mathrm{Ni}$ ) microstructure and its electrochemical performance in aqueous electrolyte. Processes 2020, 8, 343. [CrossRef]

7. Muddemann, T.; Haupt, D.; Jiang, B.; Sievers, M.; Kunz, U. Investigation and improvement of scalable oxygen reducing cathodes for microbial fuel cells by spray coating. Processes 2020, 8, 11. [CrossRef]

8. Xu, K.; Peng, J.; Chen, P.; Gu, W.; Luo, Y.; Yu, P. Preparation and characterization of porous $\mathrm{Ti} / \mathrm{SnO}_{2}-\mathrm{Sb}_{2} \mathrm{O}_{3} / \mathrm{PbO}_{2}$ electrodes for the removal of chloride ions in water. Processes 2019, 7, 762. [CrossRef]

9. Liu, S.; Gui, L.; Peng, R.; Yu, P. A novel porous Ni, Ce-doped $\mathrm{PbO}_{2}$ electrode for efficient treatment of chloride ion in wastewater. Processes 2020, 8, 466. [CrossRef]

10. Liu, Y.; Zhang, C.; Li, S.; Guo, C.; Wei, Z. Experimental study of micro electrochemical discharge machining of ultra-clear glass with a rotating helical tool. Processes 2019, 7, 195. [CrossRef]

(C) 2020 by the author. Licensee MDPI, Basel, Switzerland. This article is an open access article distributed under the terms and conditions of the Creative Commons Attribution (CC BY) license (http://creativecommons.org/licenses/by/4.0/). 